\title{
Eficácia sem razão [da matemática] ${ }^{+* 1}$
}

Danny A. V. Tonidandel ${ }^{2}$

Departamento de Engenharia de Controle e Automação - Escola de Minas Universidade Federal de Ouro Preto

Ouro Preto - MG

\section{Resumo}

Em 2003, o matemático Americano Alex Kasman (2003) escreveu um belo conto de "ficção matemática" intitulado "Unreasonable Effectiveness", uma das várias respostas existentes ao clássico artigo de Wigner (1960) "The unreasonable effectiveness of mathematics in the natural sciences". Na versão de Kasman, uma pesquisadora acaba, acidentalmente, descobrindo a resposta para a questão de como uma nova teoria encontra, em algum momento, uma utilidade prática na ciência. Isto é, como resultados abstratos, construídos sem quaisquer alicerces no "mundo real", acabam se tornando tão úteis, mesmo em áreas completamente diversas? Neste artigo é proposta uma tradução comentada deste delicioso ensaio, tanto como proposta não convencional de experiência didática quanto uma reflexão sobre os rumos do desenvolvimento científico, propiciados pela Matemática e Física. Como objetivo secundário, procura-se trabalhar a motivação do estudante na busca por soluções não triviais para problemas científicos e filosóficos.

Palavras-chave: Ensino de Física e Matemática; Filosofia da Ciência; Pensamento criativo.

\footnotetext{
${ }^{+}$The unreasonable effectiveness [of mathematics]

* Recebido: outubro de 2015. Aceito: abril de 2016.

1 (C) The Mathematical Association of America 2015. All rights reserved.

${ }^{2}$ E-mail: tonidandel@ufop.br
} 


\begin{abstract}
In 2003, the American mathematician Alex Kasman (2003) wrote a beautiful tale of "mathematical fiction" called "Unreasonable Effectiveness", one of the several responses to Wigner's classic paper "The unreasonable effectiveness of mathematics in the natural sciences" (WIGNER, 1960). In Kasman's version, a researcher ends up, accidentally, discovering the answer to the question of how a new theory finds, at some point, a practical use in science. That is, how can abstract results, built without any foundation in "real world", become so useful, even in completely diverse areas? This paper proposes a commented translation of this delightful essay, both as unconventional proposal of teaching experience and a reflection on the courses of scientific development, afforded by Mathematics and Physics. As a secondary objective, it aims to increase student's motivation in the search for non trivial solutions to scientific and philosophical problems.
\end{abstract}

Keywords: Physics and Mathematics Education; Philosophy of Science; Creative thinking.

\title{
I. Uma introdução à tradução
}

O artigo original apresentado pelo Físico Húngaro Eugene Paul Wigner (1902-1995) (WIGNER, 1960), prêmio Nobel de Física de 1963 é, sem dúvida, um dos seus trabalhos mais comentados, sendo considerado de grande importância para a história e filosofia da ciência. Nele, Wigner discorre a respeito de curiosa observação, compartilhada por muitos cientistas, do porquê uma ideia concebida originalmente nos porões da "matemática pura", sem qualquer embasamento na Física ou outra ciência natural, tem uma aplicabilidade que vai muito além do contexto em que foi desenvolvida, podendo ser inclusive utilizada para descrever, com enorme precisão, grande classe de problemas, em áreas diversas. A resposta (inconclusiva) de Wigner concentra-se na especulação de que tal "virtude" beira os limites do concebível e não possui explicação racional, i.e., que a eficácia da matemática não tem, efetivamente, qualquer razão de ser.

Após a publicação deste trabalho original, vários cientistas, ao longo dos últimos 50 anos, empreenderam suas tentativas de resposta ao enigma proposto. Entre eles pode-se contar, por exemplo, o renomado Richard Hamming (1915-1998) (HAMMING, 1980), um dos pioneiros da Ciência da Computação. Mais recentemente, cientistas como Arthur M. Lesk, da biologia molecular (LESK, 2015), Harley, Norving e Pereira (2015), também da área de computação, entre outros, enveredaram na busca de respostas para o empolgante enigma filosófico de implicações científicas (ou seria o contrário?). Quase todos, ao final de suas digressões, fornecem 
explicações plausíveis e lógicas, como era de se esperar. Há, no entanto, alguém que direciona seu pensamento em outras direções: a ficção matemática³.

Em seu ensaio, Kasman (2003) também intenciona encontrar respostas para o dilema, propondo uma solução que poderia, inclusive, ser enquadrada dentro do conceito de causalidade. Apresenta-se assim a tradução comentada do conto de Kasman, com as notas do tradutor e comentários indicados pela abreviação N.T. nas notas de rodapé. Os trechos entre colchetes, [ ], correspondem a termos e/ou comentários acrescentados pelo tradutor ao longo do texto.

\section{A eficácia sem razão}

Amanda Birnbaum começou a repensar. Poderia ela prosseguir com tudo aquilo? Ali estava ela, indo de um lado para o outro, sobre a areia seca de uma pequena ilha da qual ela nunca havia ouvido falar há poucas semanas.

Embora houvesse uma pequena população que residia casas modestas, a ilha não era reclamada por nenhum país. Até onde se poderia dizer, era tão insignificante que nenhum país estava realmente interessado nela. E, ali estava ela, olhando através do portão de aço forjado da única casa realmente grande daquelas paragens, sem ideia alguma de quem poderia residir lá. Sabia, no entanto, que estava no lugar certo. Cada uma das maiores editoras científicas deu a mesma descrição de como ela poderia encontrar a casa. Todas possuíam histórias sobre aquele estranho endereço que, tanto quanto alguém poderia recordar, era responsável por pagar qualquer preço para assinar os maiores periódicos científicos conhecidos.

Bem, mesmo que suas ideias malucas estivessem incorretas, havia algo interessante ali. Talvez ela poderia descobrir quem, neste lugar, se sentia compelido a conhecer a mais atual publicação acadêmica! Ela caminhou, então, pelo longo e sinuoso caminho em meio às ervas daninhas e flores silvestres até a porta frontal, tocando a campainha.

Suavemente, através da grossa porta de madeira, pôde ouvir o som dos carrilhões ${ }^{4}$ soando um tom familiar, anunciando sua chegada. Sentiu uma vontade súbita de sair correndo dali, mas sua curiosidade venceu e ficou esperando para ver de quem eram os passos que ela ouvia arrastarem-se lentamente em direção à porta; para ver que tipo de pessoa vivia ali.

A porta se abriu para revelar um homem bem comum: franzino, de meia idade, pele negra e com os cabelos mais brancos que ela jamais tinha visto. Ao observá-la, olhando diretamente em seus olhos, ele claramente surpreendeu-se, dando um passo para trás.

\footnotetext{
${ }^{3}$ N.T. Uma relação interessante entre os campos da física e da literatura é proposta por (ZANETIC, 2006), em que o autor discorre acerca das influências mútuas entre os dois campos do saber, especialmente em como a literatura do final do século XIX e início do XX foi influenciada pela física. Nele, o autor faz uma análise do estilo literário de escritores como Allan Poe, Gustave Flaubert, entre outros.

${ }^{4}$ N.T. Um carrilhão é um conjunto de sinos, afinados em tons diversos, muito comuns em residências, que ressoam ao sabor do vento. É parte integrante de muitas campainhas modernas.
} 
"Meu Deus", ela pensou, já reconfortada pelo fato de aquele homem não parecer ameaçador, "ele esperava outra pessoa... acho que o amedrontei. Vou tentar explicar. Eu espero que ele fale minha língua!"

"Dra. Birnbaum", disse ele, convidando-a a entrar, "Eu não esperava vê-la por aqui. Por favor, por favor, entre. Por gentileza, entre."

"Você sabe quem eu sou?!?” Perguntou Amanda enquanto acompanhava seu anfitrião ao redor do balaústre de pedra, adentrando uma pequena sala de estar.

"É claro," respondeu ele timidamente, indicando algumas opções de confortáveis assentos, desde um sofá de pelúcia a um assento de madeira. "E por que eu não saberia quem você é? Por que todo mundo está falando de você. Sua tese foi publicada há menos de um ano atrás nos Memoriais da Sociedade Americana de Matemática e já teve um profundo impacto em Biologia teórica, bem como em sua própria área, topologia de altas dimensões. Ela foi brilhante, realmente brilhante. Eu mesmo a li! Permita-me servi-la um pouco de chá.”

Ele desapareceu através de uma porta delgada, em forma de arco, em direção a uma sala que ficava atrás daquela na qual ela se encontrava, permitindo-lhe algum momento para pensar. Se houvesse uma dúvida sequer de que ela estava no lugar certo, tal comportamento a houvera eliminado. Ela estava igualmente feliz por ele haver tocado neste assunto em particular, já que ela não sabia como poderia trazê-lo à tona sem parecer louca.

"Sim", respondeu ela do outro cômodo, "é por isso que eu vim até aqui para conversar contigo." Como não houve resposta, ela pensou que ele não poderia ouvi-la.

Quando retornou alguns minutos depois, o anfitrião segurava um conjunto de chá, todo em prata. O vapor saía do bico da chaleira enquanto ele a servia. "Ah camélia", disse ele, sentindo o fragrante aroma do chá. "Mas, eu não entendo, por que você viria de tão longe somente para falar comigo sobre seu trabalho? Não há como você saber quem eu sou!”

"Não é apenas sobre minha pesquisa que eu quero falar contigo, é sobre a pesquisa em matemática em geral.” Amanda agitou sua xícara de chá sem, contudo, retirá-la do pires. Não tinha interesse em chá naquele momento. "Quando eu era estudante de graduação, um de meus professores definiu a matemática como 'o estudo de consequências necessárias de axiomas arbitrários sobre coisas sem sentido'. Meus colegas e eu, todos veteranos do curso de matemática, não gostamos da descrição. Ela parecia ignorar a utilidade da matemática. Afinal, a matemática era utilizada na Engenharia, Física, Biologia, Economia, você sabe. Discutimos sobre este paradoxo. 'Se a matemática começa com tais abstrações sem significado, por que ela se torna tão útil no final?' Houveram muitas opiniões diferentes sobre o assunto."

“Ah sim,” ele corou com um sorriso brilhante, "já ouvi esses debates muitas vezes. 'A eficácia sem razão da matemática'! 'Por que resultados em matemática abstrata, construídos muitas vezes sem quaisquer alicerces no mundo real, acabam se tornando tão úteis afinal?'”

"Isso! Isso. Como a geometria não-Euclidiana. Ao tempo em que foi primeiramente proposta, era uma espécie de truque. 'Olha o que podemos fazer se imaginarmos que linhas paralelas também podem se encontrar!' Mas então, após Riemann, Clifford, Hilbert e Einstein, 
isso já não é uma piada, é uma descrição do universo em que vivemos, embora nunca tenhamos nos dado conta disso antes."

"E," ele acrescentou, realmente apreciando aquele diálogo, "que tal a utilização de anéis não comutativos e números imaginários na física de partículas?!?”

"Sim”, concordou ela, "Quando os números imaginários foram primeiramente discutidos pelos matemáticos, eles mal eram considerados como matemática de verdade ${ }^{5}$. Agora, os físicos consideram regularmente as funções de onda de uma partícula quântica como entidades complexas, sem escrúpulos"6.

"E quando os físicos descobriram pela primeira vez a não-comutatividade em suas medidas, a supostamente inútil teoria da álgebra abstrata já estava lá, instantaneamente transformada em um ramo da matemática 'aplicada'!” E gargalhou tão alto que ela começou a ficar assustada. Ele notou sua reação e tentou se acalmar um pouco, lentamente bebericando seu chá, tentando não rir.

"Me desculpe," disse ele, "Eu não tenho uma conversa dessas desde muito tempo e... tenho um interesse especial neste assunto. Oh, mas você tinha algo a dizer e veio de tão longe. Talvez eu devesse deixá-la dizer."

Houve um pausa constrangedora enquanto Amanda tentava ordenar os pensamentos e tomar coragem.

"Então", ela retomou, "quando meus colegas e eu discutimos essas ideias na universidade, haviam dois pontos de vista principais. Alguém argumentou que a matemática nos permite estudar qualquer sistema estruturado e, desde que o universo aparenta ter algumas regras em si, nós obviamente seremos capazes de utilizar a matemática para dizer algo sobre ele, de alguma forma."

"Hummm", ele murmurou enquanto mordiscava um biscoito doce.

“Todos os outros pensavam que o universo estava, de qualquer forma, muito além de nossa compreensão. De acordo com eles, quando temos uma nova ideia matemática, nós a aplicamos ao universo por que não temos nada melhor para utilizar."

"Ah", disse tomando um gole, "é como dizem: para um homem que possui apenas um martelo como ferramenta, tudo se parece com um prego!" Lembrando que ele prometeu ficar em silêncio, parou repentinamente, fechando a boca como um zíper utilizando o polegar e o indicador.

“Certo. Mas eu tenho outra ideia. Ela era tão maluca que eu sequer mencionei aos meus amigos, mas mantive em mente como uma espécie de piada." E esperou que ele perguntasse qual era a ideia maluca, mas ele apenas sorriu, pousando o olhar sobre a mesa, como se soubesse que Amanda estava se referindo a ele.

\footnotetext{
${ }^{5}$ N.T. Uma bela história sobre a criação do conceito de números complexos pode ser encontrada no livro do escritor e historiador da ciência Paul Nahin (1998). A história da primeira utilização prática do conceito de números complexos em Engenharia, por exemplo, pode ser vista em Araújo e Tonidandel (2013).

${ }^{6}$ N.T. Considera-se que neste quesito deve-se sempre recorrer a um dos textos clássicos sobre o assunto, como o artigo de Dirac (1927).
} 
"Minha ideia," continuou, "era que outra boa explicação para o porquê da pesquisa em 'matemática pura' tornar-se tão útil algum tempo depois de sua descoberta é que o universo em si se auto-organiza para se encaixar em nossas descobertas."

"Oh," disse ele, piscando os olhos rapidamente enquanto mantinha o sorriso. "E por que você veio de tão longe para falar comigo sobre isto?"

"Por que, eu acho que você é quem está fazendo isso."

Ele assentiu vagarosamente com a cabeça, como se estivesse admitindo que era verdade. Isto a surpreendeu, já que ela esperava uma negativa. Esperava ouvir que estava louca. Era uma ideia louca, afinal... não era?

Houve mais um silêncio desconfortável.

"Então," disse ela à queima roupa, "é verdade?"

"Entre você e eu?" ele olhou de um lado para o outro como se esperasse encontrar alguém espionando da sala de estar. "Cá entre nós, é sim, e é um trabalho ingrato."

"Então, isso faz de você... você sabe... você é.... O Criador do universo?"

"Rá!" ele gritou tão alto que ela quase cuspiu o chá. "Se eu fosse um dos criadores, você acha que eu estaria aqui nesse planetinha no meio do nada? Sem querer ofender. Não, não, eu apenas tenho feito isso por algumas centenas de anos e após mais uns duzentos anos eu poderei me aposentar para uma bela realidade alternativa com a qual tenho sonhado."

"Ela ainda tentava processar tudo isso. Então, você quer dizer que sempre que descobrimos algo todo o universo muda?"

"Bem, eu não diria todo o universo e nem toda descoberta. Quando encontro um resultado que acho interessante ou divertido, eu encontro um jeito de incorporá-lo no universo... mas apenas localmente. É por isso que os seus cosmologistas têm ficado tão confusos em suas teorias. Em outros distritos, outros com o meu trabalho podem ter diferentes gostos em matemática, diferentes ideias de como a 'realidade' poderia ser. Na verdade, é essa diversidade de possibilidades que os criadores mais gostam... e é por isso que eu tenho um emprego!" Ele estava imensamente feliz em ter alguém para conversar a respeito, após tanto tempo em silêncio. Um sorriso de contentamento iluminou seu rosto e ele se inclinou para trás em seu assento como se nunca estivesse tão confortável em sua vida.

"Mas então," ela tinha tantas perguntas que sentia dificuldade em decidir qual delas fazer primeiro, "se..."

"Espere!" ele a interrompeu ajeitando-se no assento com uma expressão preocupada. "Por favor, você precisa me dizer como me encontrou. Eu não deveria ser descoberto, sabe."

"Bem," ela disse, incapaz de olhar em seus olhos, "você se lembra de minha tese?"

"Muito bem!" Seus olhos se iluminaram de um modo que ela achou lisonjeiro. Ele realmente tinha gostado de seu trabalho. "Você notou que a cohomologia de uma certa classe de variedades diferenciáveis ${ }^{7}$ de $n$-dimensões têm algumas propriedades algébricas bizarras.

\footnotetext{
${ }^{7}$ N.T. Poder-se-ia dizer que o estudo das variedades diferenciáveis (ou manifolds) formam um ramo da topologia, que é um campo da matemática que considera as propriedades de objetos que não se alteram, em essência, quando
} 
Você chamou tais variedades de 'variedades imunológicas' por ter notado que seu comportamento lembrava um sistema imunológico. E embora você diga na introdução que não é especialista em Biologia, a ideia motivou sua nomenclatura ao longo da tese. Algumas variedades imunológicas são saudáveis, outras não. Algumas têm inclusive doenças autoimunes!"

"Apenas nomes que eu dei para me auxiliarem a descrever e entender a estrutura matemática."

"Talvez, mas seus cientistas não conseguiram entender o sistema imunológico antes, e há tanto espaço para belas e ricas descobertas crescerem além de suas próprias. Eu mal podia esperar para começar a trabalhar nisto. Você já deve ter visto como eu fui capaz de trazê-las para desempenharem importante papel na melhoria das vacinas e, em poucos meses, pesquisadores das ciências médicas, estudando a esclerodermia, descobrirão que poderão usar o Teorema da dualidade de Serre para..."

"Mas," ela o interrompeu, "você cometeu um erro. Quero dizer, eu cometi um erro na prova da equação 3.6. As álgebras micrométricas não necessitam ser simplesmente conectadas e, por isso, a definição 3.9 realmente não faz nenhum sentido e..."

"Não", ele ficou boquiaberto, derrubando o último pedaço de seu biscoito. "A equação 3.6 não! Mas ela era uma das minhas partes favoritas. Eu a usei em toda parte!"

"Sim, eu sei. E é por isso que eu o encontrei. Veja, eu encontrei o erro logo após os memoriais terem sido publicados. Não foi fácil, mas pude fazer com que toda a cópia com o erro fosse recolhida e substituída com a versão correta... toda a cópia exceto aquela que foi enviada separadamente, por correio privado, para sua casa. É por isso que eu sabia..."

"Meu Deus," disse ele agitando seu chá vigorosamente. "Meu Deus, o quão descuidado eu fui! Teremos que fazer algo a respeito, não é? Sim, algo terá que ser feito a respeito"8

submetidos a transformações contínuas arbitrárias, tais como "esticar" ou "flexionar", como pode ser feito com um pedaço de borracha. Por exemplo, na Teoria Geral da Relatividade de Einstein, um buraco de minhoca é uma variedade. O espaço-tempo quadridimensional também. Outro exemplo vem da Engenharia: imagine um robô planar (de duas dimensões) em forma de braço, que possui duas juntas (ombro e cotovelo, i.e., dois graus de liberdade). O conjunto de coordenadas que representam os ângulos que as juntas deste robô podem assumir formam um Toro bi-dimensional (um Toro é uma figura que tem o formato de uma "rosquinha"), que é uma variedade bidimensional imersa em um espaço Euclidiano de dimensão 3 (escrevendo em uma expressão algébrica). Em outras palavras, a "rosquinha" é um objeto tridimensional que localmente aparenta ter duas dimensões.

8 N.T. Percebe-se, de certa forma, a tentativa de fornecer uma explicação causal para o sucesso da matemática em outras áreas, como Física ou Biologia, mesmo que ficcional. Com o termo causalidade, intenciona-se conjecturar se há uma relação direta entre as descobertas na matemática e aplicações futuras das descobertas em sistemas de naturezas diversas. Na Filosofia, o princípio de causalidade é a condição segunda a qual uma causa produz um efeito. Na Ciência o conceito é bem similar: a relação de causalidade de um sistema pode ser expressa naquele em que a saída em um instante de tempo $t_{0}$ pode ser conhecida se o valor de entrada $\mathrm{x}(\mathrm{t})$ deste sistema for conhecido para $\mathrm{t} \leq t_{0}$. Em outras palavras, o valor de saída no instante presente depende apenas do valor presente e passado da entrada. Qualquer sistema prático que opera em tempo real deve ser, necessariamente, causal, razão pela qual estes sistemas são também chamados de sistemas físicos. Se a resposta do sistema começar antes da entrada, isto significa que ele conhece a entrada no futuro e atua com base neste conhecimento antes da entrada ser aplicada. Um sistema que viola a causalidade é chamado de não-causal. Aliás, por mais estranho que pareça, um sistema não-causal é perfeitamente plausível, desde que a variável independente seja outra que não o "tempo" (e.g., o espaço). Por exemplo, o campo elétrico produzido por uma carga $q$ localizada em um ponto do espaço forma um sistema não-causal. 


\section{Referências}

ARAÚJO, A. E. A.; TONIDANDEL, D. A.V. Steinmetz and the concept of phasor: a forgotten story. Journal of Control Automation and Electrical Systems, v. 24, p. 388-395, Springer, 2013.

DIRAC, P. M. The physical interpretation of quantum dynamics. Proceedings of the Royal Society of London, v. 1, n. A113, p. 621-641, 1927.

HAMMING, R. W. The unreasonable effectiveness of mathematics. The American Mathematical Monthly, v. 87, n. 2, p. 81-90, 1980.

HARLEY, A.; NORVING, P.; PEREIRA, F. The Unreasonable Effectiveness of Data. IEEE Intelligent Systems, v. 24, n. 2, p.8-12. Disponível em: <http://goo.gl/Ibrk1C>. Acesso em: 15 set. 2015.

KASMAN, A. Unreasonable effectiveness. Math Horizons. Mathematical Association of America Press, abr. 2003. Disponível também no livro Reality Conditions. MAA Press, 2005. ISBN 08-838-5552-6.

LESK, A. M. The unreasonable effectiveness of mathematics in molecular biology. The Mathematical Intelligencer, v. 22, n. 2, p. 28-37, 2000. Disponível em: <http://goo.gl/K7Dcr6>. Acesso em: 15 set. 2015.

NAHIN, P. J. An imaginary tale: the story of $\sqrt{-1}$. 1. ed. Princeton University Press: 1998.

WIGNER, E. P. The unreasonable effectiveness of mathematics in the natural sciences. Communications on Pure and Applied Mathematics. v. 13, p. 1-14, 1960. 